\title{
Effects of polycyclic musks HHCB and AHTN on steroidogenesis in H295R cells
}

\author{
Zhuona Li, Nuoya Yin, Qian Liu, Chang Wang, Thanh Wang, Yichen Wang, Guangbo Qu, Jiyan Liu, \\ Yaqi Cai, Qunfang Zhou*, Guibin Jiang
}

State Key Laboratory of Environmental Chemistry and Ecotoxicology, Research Center for Eco-Environmental Sciences, Chinese Academy of Sciences, P.O. Box 2871, Beijing 100085, China

\section{H I G H L I G H T S}

- HHCB and AHTN can inhibit progesterone and cortisol production.

- HHCB and AHTN can down-regulate 3BHSD2 and CYP21.

- HHCB and AHTN can up-regulate CYP17, CYP11B1 and CYP11B2.

- AHTN can influence steroidogenesis by affecting MC2R expression.

\section{A R T I C L E I N F O}

\section{Article history:}

Received 8 April 2012

Received in revised form 13 September

2012

Accepted 16 September 2012

Available online 17 October 2012

\section{Keywords:}

HHCB

AHTN

H295R

Steroidogenesis

Adrenocortical toxicity

\begin{abstract}
A B S T R A C T
1,3,4,6,7,8-Hexahydro-4,6,6,7,8,8-hexamethylcyclopenta-( $\gamma$ )-2-benzopyran (HHCB) and 7-acetyl-1,1,3,4,4,6-hexamethyl-1,2,3,4-tetrahydronaphthalene (AHTN) are widely used in personal care products. Previous studies showed that HHCB and AHTN can be found in various environmental matrices and have potential endocrine disrupting effects. However, the effects on adrenocortical function of HHCB and AHTN are not fully understood. This study evaluated the influences of HHCB and AHTN on seven steroid hormones (progesterone, aldosterone, cortisol, 17 $\alpha$-OH-progesterone, androstenedione, 17 $\beta$-estradiol, and testosterone) and 10 genes involved in steroidogenic pathways (HMGR, StAR, CYP11A1, 3ßHSD2, CYP17, CYP21, CYP11B1, CYP11B2, 17BHSD, and CYP19) using the H295R cell line in the absence and presence of 8-Br-cAMP. $M C 2 R$ transcription on the cell membrane was also examined to further investigate the effects of HHCB and AHTN on adrenal steroidogenesis. The results demonstrated that HHCB and AHTN could inhibit progesterone and cortisol production mainly by the suppression of 3BHSD2 and CYP21. Meanwhile, high concentrations of AHTN can affect the sensitivity of H295R cells to ACTH by disrupting $M C 2 R$ transcription. Overall, the results indicate that high concentrations of HHCB and AHTN can affect steroidogenesis in vitro using the H295R cell line.
\end{abstract}

() 2012 Elsevier Ltd. All rights reserved.

\section{Introduction}

Polycyclic musks (PCMs), predominantly 1,3,4,6,7,8-hexahy dro-4,6,6,7,8,8-hexamethylcyclopenta- $(\gamma)$-2-benzopyran (HHCB) and 7-acetyl-1,1,3,4,4,6-hexamethyl-1,2,3,4-tetrahydronaphthalene (AHTN), are widely used as essential fragrance ingredients in cosmetics, perfumes, laundry cleaning detergents and other consumer products. Due to their widespread use, lipophilicity, and persistence, PCMs have been detected in various environmental matrices including freshwater, seawater, sediments, biota, and even humans (Zeng et al., 2008; Hu et al., 2010, 2011; Hutter et al., 2010). The wide distribution of PCMs and their polycyclic nature raise the question whether PCMs have the potential to disturb endocrine functions. There are increasing evidences that

\footnotetext{
* Corresponding author. Tel.: +86 10 62849334; fax: +86 1062849339

E-mail address: zhouqf@rcees.ac.cn (Q. Zhou).
}

PCMs could exert estrogenic, anti-estrogenic, anti-androgenic, and anti-progestagenic activities, and they could also cause reproductive disorder and population decline of the polychaete (Capitella species I) (Seinen et al., 1999; Bitsch et al., 2002; Schreurs et al., 2004, 2005a, 2005b; Yamauchi et al., 2008; Ramskov et al., 2009). Most previous studies are focused on the reproductive effects, but less attention is paid to other endocrine organs, such as the adrenal gland. Because of high lipid content, copious blood supply and steroidogenic capacity, the adrenal gland is likely to accumulate lipophilic chemicals (Ribelin, 1984). Thus, it is important to assess the adrenocortical toxicity of HHCB and AHTN.

The adrenal gland is one of the most important endocrine organs in human and, unlike the gonads, essential for survival (Sanderson, 2006). All steroidogenic processes take place in the adrenal cortex, which is responsible for production of three major types of steroid hormones: mineralocorticoids, glucocorticoids, and the sex hormones (Li and Wang, 2005). The H295R cell line, 
derived from an adrenocortical carcinoma, preserves the intact steroidogenic pathways in the normal adrenal cortex and allows the measurement of alterations in gene transcription, enzyme activity and hormone production at the same time, which makes it a unique bioassay model for evaluating the effects of chemicals on steroidogenic pathways and adrenocortical toxicity (Fig. 1) (Gazdar et al., 1990; Johansson et al., 2002; Oskarsson et al., 2006; Hecker and Giesy, 2008). Additionally, H295R cells treated with forskolin (a cAMP inducer) could make the steroidogenic transcript profiles more similar to those in normal human adrenal cells, which further suggests that the H295R cell line is particularly suitable for the risk assessment of adrenocoritical toxicity (Oskarsson et al., 2006). Activation of cAMP is also critical for the investigation of adrenocorticotropic hormone (ACTH)'s effect on the steroidogenic process under biological conditions. ACTH is released from the pituitary gland and stimulates the production of steroid hormones by activating adenylyl cyclase to elevate cAMP after binding to melanocortin 2 receptor $(M C 2 R)$ on the cell membrane (Sewer and Waterman, 2003; Li and Wang, 2005).

In order to evaluate the effects of the tested PCMs on steroidogenic pathways and adrenocortical toxicity, we exposed H295R cells to HHCB and AHTN at different concentrations in the absence and presence of $1 \mathrm{mM} 8$-Br-cAMP (a cAMP analog) for $48 \mathrm{~h}$. Production of seven steroid hormones (progesterone, aldosterone, cotisol, $17 \alpha-\mathrm{OH}$-progesterone, androstenedione, testosterone, and $17 \beta$-estradiol) and transcription of ten genes encoding the steroidogenic enzymes (HMGR, StAR, CYP11A1, 3ßHSD2, CYP17, CYP21, CYP11B1, CYP11B2, 17ßHSD, and CYP19) were investigated. MC2R transcription on the cell membrane was also examined to further elucidate the effects of $\mathrm{HHCB}$ and AHTN on adrenal steroidogenesis.

\section{Materials and methods}

\subsection{Chemicals}

Tonalide (AHTN, 98\%) was obtained from LGC-Promochem and Galaxolide (HHCB, 95\%) was from Beijing Wohai Global Technology Co., Ltd. 8-Bromo-cyclic adenosine monphosphate (8-Br-cAMP) was purchased from Sigma-Aldrich (St. Louis, MO, USA). Dimethyl sulfoxide (DMSO, 99.9\%) was purchased from Amresco (Shanghai, China).

\subsection{Cell culture}

The H295R human adrenocortical carcinoma cell line was purchased from the American Type Culture Collection (ATCC\#CRL-2128, Manassas, VA, USA) and cultured in $75 \mathrm{~cm}^{2}$ petri dish with $12 \mathrm{~mL}$ of DMEM/F-12 (HyClone, SH30023.01B) at $37^{\circ} \mathrm{C}$ containing $95 \%$ air and $5 \% \mathrm{CO}_{2}$ atmosphere. The medium was supplemented with $1 \%$ insulin-transferrin-selenium-G (ITES-G, Gibco BRLm, 41400-045), 1\% penicillin-streptomycin (GibcoBRL, 15140122), and 2.5\% Nu-Serum (BD Bioscience, 35500). The medium was refreshed two or three times a week and cells were detached from the culture dish for subculture. Cells were used between passages 5 and 10 after thawing from liquid nitrogen.

\subsection{Cell exposure}

Test chemicals were dissolved in DMSO and the final concentration of vehicle, DMSO, in the exposure medium was $0.1 \%(v / v)$. For cell viability measurements, H295R cells were seeded in a 96-well plate at a concentration of $6 \times 10^{5}$ cells $\mathrm{mL}^{-1}$ in $200 \mu \mathrm{L}$ of medium per well. After $24 \mathrm{~h}$, cells were exposed to $0.25,2.5,25 \mu \mathrm{M}$ of tested chemicals dissolved in DMSO and the medium was refreshed with phenol red-free DMEM/F-12 medium (HyClone, SH30272.01) supplemented with $1 \%$ ITES-G, $1 \%$ penicillin-streptomycin, and $2.5 \%$ charcoal stripped fetal bovine serum (Biological industries, 04-201-1A). After $48 \mathrm{~h}$ of exposure, cell viability was evaluated by Alamar Blue assay. Briefly, resazurin was added directly to the 96-well plates to a final concentration of $10 \mu \mathrm{M}$ without removing the medium. After incubating for $2 \mathrm{~h}$ at $37^{\circ} \mathrm{C}, 100 \mu \mathrm{L}$ of medium was transferred to a 96 -well black polystyrene microplate, and the fluorescence signal $(530 \mathrm{~nm} / 590 \mathrm{~nm}$, excitation/emission) was subsequently measured using spectral scanning multimode reader (Thermo Scientific Varioskan Flash).

For the measurement of hormone and gene transcription, the initial plating cell density was $1.2 \times 10^{6}$ cells well $^{-1}$ in $2.5 \mathrm{~mL}$ of cell medium per well of a six-well plate. $1 \mathrm{mM} 8$-Br-cAMP was added to mimic the ACTH upsurge according to previous studies

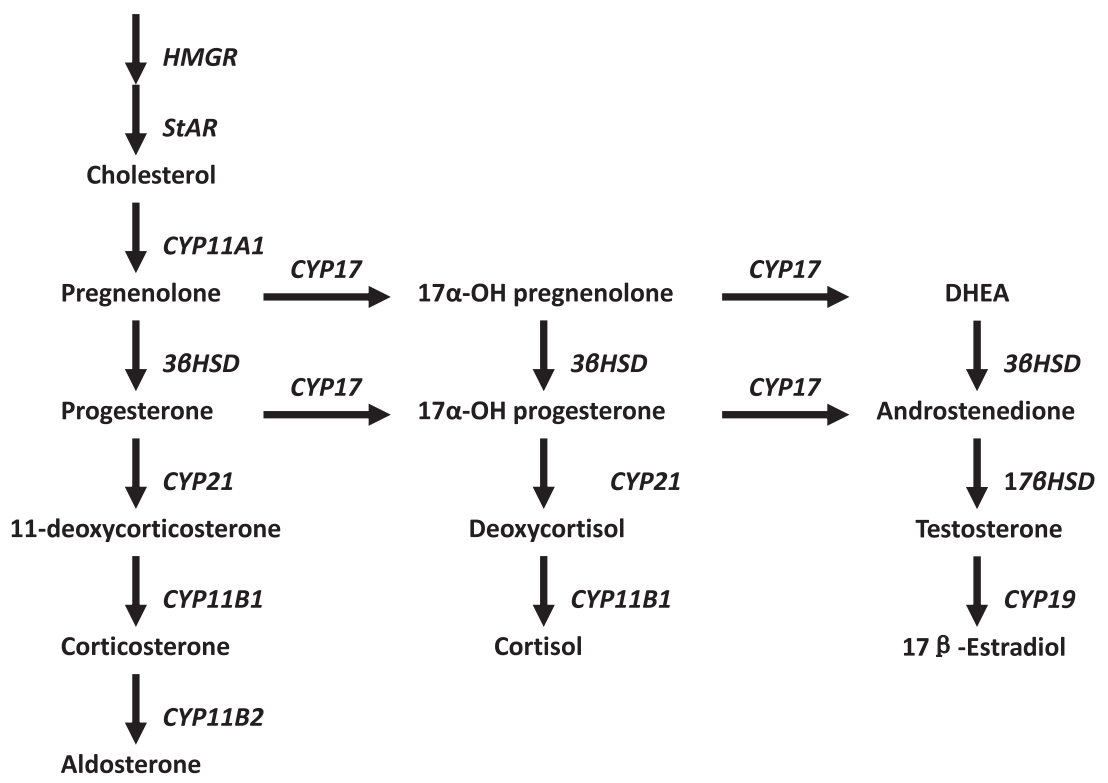

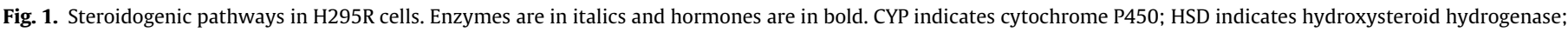
DHEA indicates dehydroepiandrosterone. Modified based on the diagram of Furuta et al. (2008), Ma et al. (2011) and Li et al. (2004). 
(Li and Wang, 2005; Furuta et al., 2008). The culture medium was changed after $24 \mathrm{~h}$, and cells were exposed to different concentrations of the tested PCMs in the absence and presence of $1 \mathrm{mM}$ 8 -Br-cAMP for $48 \mathrm{~h}$. At the end of exposure, the culture medium was collected for hormone measurement. After removal of the medium, cells were lysed by the addition of $1 \mathrm{~mL}$ well ${ }^{-1}$ of Trizol reagent (Invitrogen, 15596018) for total RNA isolation. All samples were stored at $-80^{\circ} \mathrm{C}$ prior to analysis.

\subsection{Hormone measurement}

Aldosterone, cortisol, progesterone, testosterone and $17 \beta$ estradiol were measured using RIA kits from Beijing North Institute of Biological Technology. 17 $\alpha$-OH-progesterone and androstenedione were determined using ELISA kits from DRG International Inc. All kits were used in accordance with manufacturers' recommendations.

\subsection{RNA isolation}

Frozen samples were thawed on ice and then $200 \mu \mathrm{L}$ of chloroform was added to each tube. Samples were inverted gently for $5 \mathrm{~min}$ at room temperature. After centrifugation at $12000 \mathrm{~g}$ for $10 \mathrm{~min}$ at $4^{\circ} \mathrm{C}, 400 \mu \mathrm{L}$ of the top aqueous phase was transferred to a fresh microcentrifuge tube and an equal volume of isopropanol was added to each tube. Samples were mixed thoroughly by inversion. The mixtures were incubated at $4{ }^{\circ} \mathrm{C}$ for $15 \mathrm{~min}$. The samples were then again centrifuged at $10000 \mathrm{~g}$ for $10 \mathrm{~min}$ at $4{ }^{\circ} \mathrm{C}$. The nucleic acid pellet was washed twice with $1 \mathrm{~mL}$ of ice-cold $70 \%$ ethanol and centrifuged at $7500 \mathrm{~g}$ for $10 \mathrm{~min}$ at $4{ }^{\circ} \mathrm{C}$. After centrifugation, the supernatant was discarded and the pellet was dried at room temperature. Finally, the pellet was resuspended in $30 \mu \mathrm{L}$ of nuclease-free water. RNA integrity was estimated using ethidium bromide-stained agarose gel electrophoresis (1\%). Purity and concentration of the isolated RNA were measured by absorbance using Thermo Scientific NanoDrop 2000 at 260 and $280 \mathrm{~nm}$. RNA preparations were considered acceptable for RT-PCR when the ratio 260/280 were higher than 1.8 .

\section{6. cDNA synthesis}

Complementary DNA (cDNA) was synthesized from $2 \mu \mathrm{g}$ of total RNA combined with $1 \mu \mathrm{L}\left(0.5 \mu \mathrm{g} \mu \mathrm{L}^{-1}\right)$ of Oligo $(\mathrm{dT})_{18}$ in nucleasefree water to a final volume of $15 \mu \mathrm{L}$. Reaction mixtures were denatured at $70{ }^{\circ} \mathrm{C}$ for $5 \mathrm{~min}$ and then immediately cooled on ice. Reverse transcription was performed in $10 \mu \mathrm{L}$ of mixture including $1.5 \mu \mathrm{L}$ of dNTP Mix (Promega, U1515, USA), $0.5 \mu \mathrm{L}$ of RiboLock ${ }^{\mathrm{TM}}$ RNase Inhibitor (Fermentas, E00381, USA), $5 \mu \mathrm{L}$ of M-MLV RT $5 \times$ Buffer, $1 \mu \mathrm{L}$ of M-MLV Reverse Transcriptase (Promega, $\mathrm{M} 1705$, USA) and $2 \mu \mathrm{L}$ of nuclease-free water. Reaction mixes were incubated at $42{ }^{\circ} \mathrm{C}$ for $60 \mathrm{~min}$ and then terminated by incubation at $87^{\circ} \mathrm{C}$ for $1 \mathrm{~min}$. Samples were stored at $-20^{\circ} \mathrm{C}$ until analysis.

\subsection{RT-PCR analysis}

Real-time PCR (quantitative PCR) was performed by using Mx3005P (Stratagene, USA) in $200 \mu \mathrm{L}$ thin-wall 8 strip PCR tubes. RT-PCR reaction mixtures of $20 \mu \mathrm{L}$ was combined with $1 \mu \mathrm{L}$ of cDNA sample, $5 \mu \mathrm{L}$ of nuclease-free water, $10 \mu \mathrm{L}$ of GoTaq ${ }^{\circledR}$ qPCR Master Mix (Promega, A6001, USA), $2 \mu \mathrm{L}(2 \mu \mathrm{M})$ of forward and reverse primers. Primer sequences for gene in the experiment have been described previously (Table 1) (Zhang et al., 2005; Damilakis et al., 2010).

The thermal cycle profile was denatured at $95^{\circ} \mathrm{C}$ for $2 \mathrm{~min}$, followed by 45 cycles of denaturation at $95^{\circ} \mathrm{C}$ for $15 \mathrm{~s}$, annealing at $59{ }^{\circ} \mathrm{C}$ for $30 \mathrm{~s}$, extension at $72{ }^{\circ} \mathrm{C}$ for $25 \mathrm{~s}$; and a final cycle of $95^{\circ} \mathrm{C}$ for $25 \mathrm{~s}, 59^{\circ} \mathrm{C}$ for $25 \mathrm{~s}$, and $95^{\circ} \mathrm{C}$ for $30 \mathrm{~s}$. The melting curve was performed during the $59^{\circ} \mathrm{C}$ stage of the final cycle to ensure that primer-dimers and other nonspecific products were omitted.

The comparative $C_{t}$ method was used to quantify fold changes in gene transcription (Livak and Schmittgen, 2001). The PBGD housekeeping gene, which encodes for a member of the hydroxymethylbilane synthase superfamily, showed relatively stable expression and has no known pseudogenes. Optimization and validation experiments were carried out to ensure that the amplification efficiencies for all tested genes, including the target genes and the housekeeping gene, were at reasonable range before the quantitative analysis of RT-PCR using the comparative $C_{t}$ method. $C_{t}$ (the cycle at which the fluorescence signal was first significantly different from background) was determined for each reaction. $C_{t}$ values for each gene were normalized to the respective house-keeping gene to produce $\Delta C_{t}$. The difference between $\Delta C_{t}$ values for the vehicle control and exposed cells was defined as $\Delta \Delta C_{t}$. Fold changes were quantified by the following relationship:

$N$-fold change $=2^{-\Delta \Delta \mathrm{Ct}}=2^{-\Delta(\Delta \mathrm{Ct} \text {,control- } \Delta \mathrm{Ct} \text {,exposure })}$

Gene transcription levels were measured in triplicate for each control or exposed cell culture and each exposure was repeated at least three times.

\subsection{Statistical analysis}

All data analysis was performed with SPSS 13.0. Results were presented as mean \pm SD $(n=3)$. Statistical analyses of hormone production and gene transcription profiles between control and exposed cells were evaluated by one-way analysis of variance (ANOVA) followed by post hoc Dunnett's tests.

\section{Results}

\subsection{Effects of HHCB and AHTN on H295R cell viability}

Preliminary experiments based on Alamar Blue assay showed that no cytotoxicity was observed at currently tested concentrations $(0.25,2.5,25 \mu \mathrm{M})$ of PCMs (data not shown). This dose range is used for the following experiments to estimate PCMs effects on steroidogenesis without causing nonspecific cytotoxicity.

\subsection{Effects of HHCB and AHTN on hormone production}

In $25 \mu \mathrm{M}$ HHCB basal treatments without 8-Br-cAMP (Fig. 2, white bars), progesterone and cortisol production were decreased by $39 \%$ and $27 \%$ of the basal control, respectively. Aldosterone, $17 \alpha-\mathrm{OH}$-progesterone, androstenedione, testosterone, and $17 \beta$-estradiol were not significantly altered at any of the tested concentration. In $25 \mu \mathrm{M}$ HHCB cAMP-induced treatments (Fig. 2, black bars), progesterone and cortisol production were decreased by $36 \%$ and $16 \%$ of the cAMP-induced control, respectively. All the other hormones tested did not exhibit any significant response.

In AHTN basal treatments (Fig. 3, white bars), a dose-dependent decrease in progesterone production was observed (reduced by $27 \%, 24 \%, 45 \%$ of the basal control at $0.25,2.5,25 \mu \mathrm{M}$, respectively). Cortisol production was reduced by $25 \%$ of the basal control at $25 \mu \mathrm{M}$, whereas no statistically significant changes were observed for aldosterone, $17 \alpha-\mathrm{OH}$-progesterone, androstenedione, testosterone, and $17 \beta$-estradiol. In AHTN cAMP-induced treatments (Fig. 3, black bars), progesterone production was also inhibited in a dosedependent manner (reduced by 15\%, 33\%, 79\% of the cAMPinduced control at $0.25,2.5,25 \mu \mathrm{M}$, respectively). There was a significant reduction in cortisol, $17 \alpha-\mathrm{OH}$-progesterone, testosterone, and $17 \beta$-estradiol production at $25 \mu \mathrm{M}$ (decreased by $37 \%, 41 \%$, 
Table 1

Sequences of primers for steroidogenic enzymes.

\begin{tabular}{lll}
\hline Gene & Sense primer $\left(5^{\prime}-3^{\prime}\right)$ & Antisense primer $\left(5^{\prime}-3^{\prime}\right)$ \\
\hline PBGD & CTG GAG GAG TCT GGA GTC TAG & TGG AAT GTT ACG AGC AGT GAT G \\
HMGR & TTC AGG TTC CAA TGG CAA CAA C & GCC ACG AGT CAT CCC ATC TG \\
StAR & ACC TTG ATC TCC TTG ACA TTG G \\
CYP11A1 & GAG ATG GCA CGC AAC CTG AAG & CTT AGT GTC TCC TTG ATG CTG GC \\
$3 \beta H S D 2$ & AGC ATC TTC TGT TTC CTG GCA & TCT CCT TCA GTT CCT TCT CTT C \\
CYP21 & ACC TCA GTT TCT CCT TTA TTG C & AGA GCC AGG GTC CTT CAC \\
CYP11B2 & TCC AGG TGT GTT CAG TAG TTC C & GAA GCC ATC TCT GAG GTC TGT G \\
CYP17 & GGC ACC AAG ACT ACA GTG ATT G & AGA GTC AGC GAA GGC GAT AC \\
CYP11B1 & GGT TTG CCA GGC TAA GC & CAA ACT GCC CAG AGG ACA G \\
$17 \beta H S D$ & TTC ATG GAG AAG GTG TTG G & AAG ACT TGC TTG CTG TGG \\
CYP19 & TTG GAA ATG CTG AAC CCG ATA C AGT GAG GAG CAG GAC \\
ACTH & ACT GTC CTC GTG TGG TTT TG & AGA TGA AGA CCC CGA GCA G \\
\hline
\end{tabular}
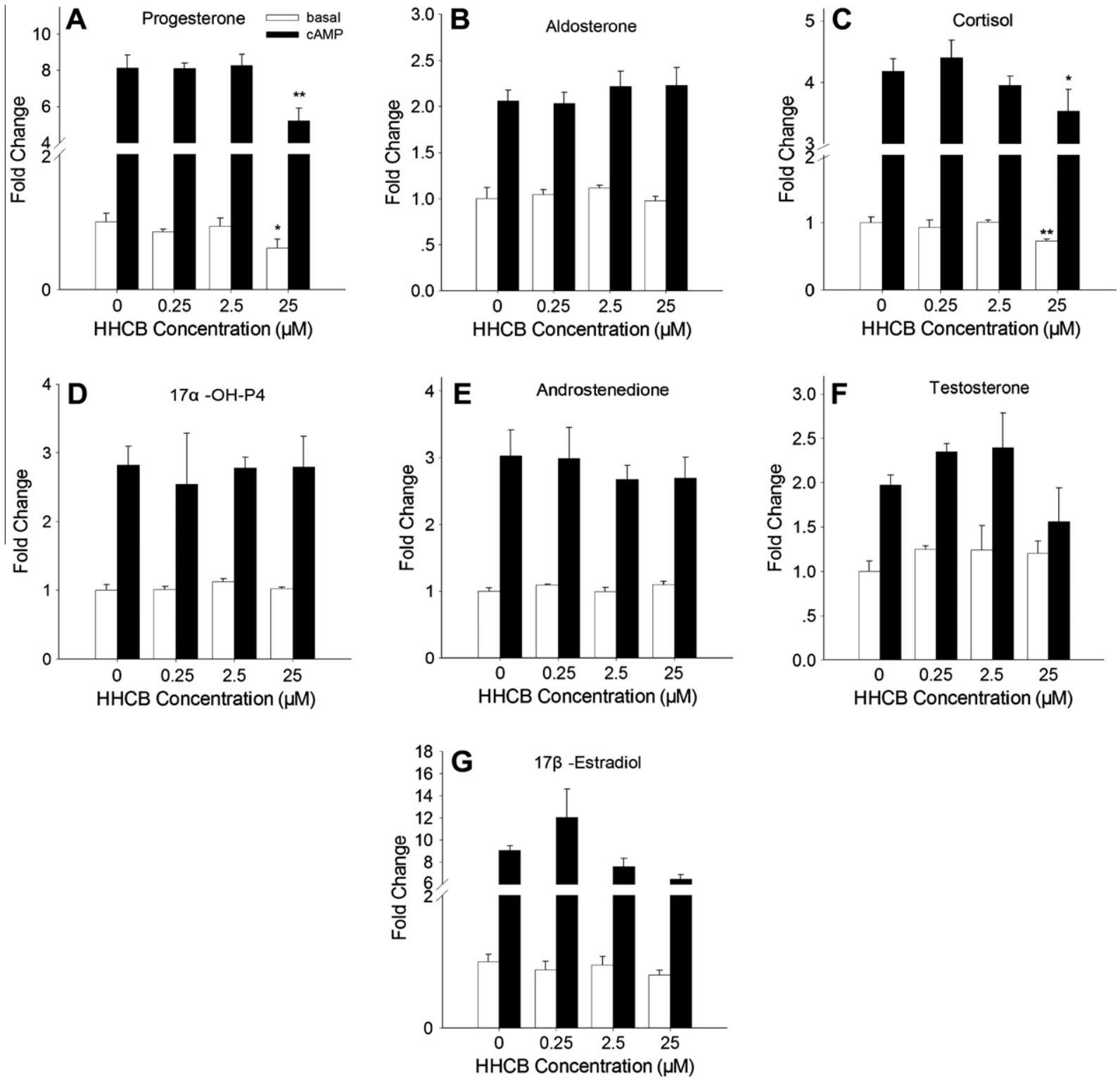

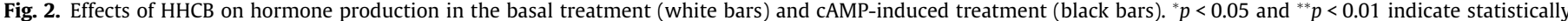
significant differences between treatment and control.

$36 \%$, and $50 \%$ of the cAMP-induced control, respectively). However, no significant changes were observed for androstenedione.
The results suggested that $\mathrm{HHCB}$ and AHTN could interfere with steroidogenesis through inhibition of progesterone and cortisol production, whereas no clear response patterns were observed 

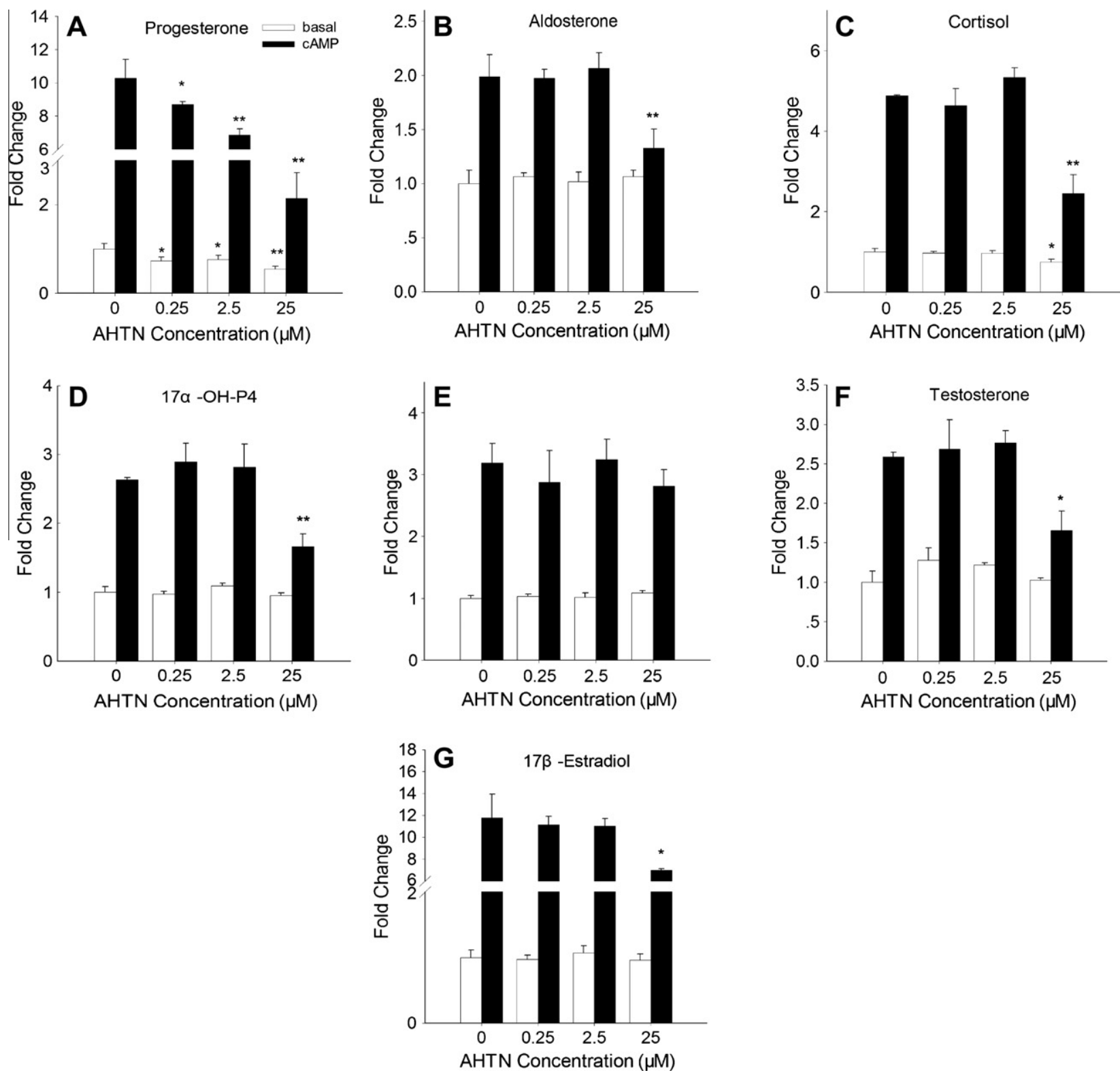

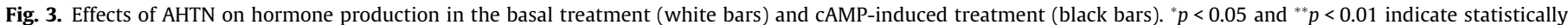
significant differences between treatment and control.

for the other hormones although $17 \alpha-\mathrm{OH}$-progesterone, testosterone, and $17 \beta$-estradiol were suppressed at $25 \mu \mathrm{M}$ in AHTN cAMPinduced treatments. In order to examine potential mechanisms of the tested PCMs on hormone production, transcription levels of corresponding genes encoding steroidogenic enzymes were further determined.

\subsection{Effects of HHCB and AHTN on steroidogenic gene transcription involved in progesterone biosynthesis}

Progesterone is an important precursor to other steroid hormones in the adrenal glands, such as aldosterone, cortisol, testosterone, and $17 \beta$-estradiol. Progesterone is converted from cholestrol via sequential reactions catalyzed by $H M G R$, StAR, CYP11A1, and 3BHSD2 (Fig. 1). As shown in Table $225 \mu \mathrm{M} \mathrm{HHCB}$ down-regulated $3 \beta H S D 2$ by $71 \%$ of the basal control and by $60 \%$ of the cAMP-induced control. However, none of the tested concentrations significantly affected gene transcription levels of $H M G R$,
StAR, and CYP11A1. Exposure to $25 \mu \mathrm{M}$ AHTN resulted in the down-regulation of $3 \beta H S D 2$ by $43 \%$ of the basal control and by $60 \%$ of the cAMP-induced control. No significant differences were noted in the transcription profiles of the other three genes for AHTN.

\subsection{Effects of HHCB and AHTN on steroidogenic gene transcription involved in aldosterone and cortisol biosynthesis}

Aldosterone is converted from progesterone via sequential reactions catalyzed by CYP21, CYP11B1 and CYP11B2. Cortisol is converted from $17 \alpha-\mathrm{OH}$-progesterone catalyzed by CYP21 and CYP11B1 (Fig. 1). CYP21 was down-regulated by $43 \%$ of the basal control and by $60 \%$ of the cAMP-induced control under $25 \mu \mathrm{M}$ HHCB. CYP11B1 was up-regulated by 2.39-fold of the basal control and by 7.63 -fold of the cAMP-induced control. Meanwhile, CYP11B2 was up-regulated by 1.71 -fold of the basal control and by 3.52 -fold of the cAMP-induced control. When H295R cells were 
Table 2

Fold changes of HHCB and AHTN on gene expression in the basal and cAMP-induced treatment.

\begin{tabular}{|c|c|c|c|c|c|c|c|c|c|c|c|c|}
\hline Chemical & Treatment & $\begin{array}{l}\text { Concentration } \\
(\mu \mathrm{M})\end{array}$ & StAR & $H M G R$ & CYP11A & $3 \beta H S D 2$ & CYP17 & CYP21 & CYP11B1 & CYP11B2 & $17 \beta H S D$ & CYP192a \\
\hline \multirow[t]{8}{*}{ HHCB } & Basal & 0 & $1.01 \pm 0.20$ & $1.00 \pm 0.09$ & $1.01 \pm 0.13$ & $1.00 \pm 0.02$ & $1.01 \pm 0.13$ & $1.01 \pm 0.16$ & $1.01 \pm 0.18$ & $1.02 \pm 0.23$ & $1.04 \pm 0.34$ & $1.03 \pm 0.28$ \\
\hline & & 0.25 & $1.16 \pm 0.16$ & $1.15 \pm 0.16$ & $1.27 \pm 0.17$ & $0.84 \pm 0.15$ & $1.16 \pm 0.23$ & $1.08 \pm 0.08$ & $1.24 \pm 0.21$ & $0.98 \pm 0.05$ & $1.41 \pm 0.40$ & $1.35 \pm 0.23$ \\
\hline & & 2.5 & $1.25 \pm 0.18$ & $1.17 \pm 0.55$ & $1.32 \pm 0.10$ & $0.68 \pm 0.12^{* *}$ & $1.04 \pm 0.24$ & $1.14 \pm 0.18$ & $1.12 \pm 0.25$ & $1.12 \pm 0.30$ & $1.45 \pm 0.10$ & $0.96 \pm 0.20$ \\
\hline & & 25 & $1.47 \pm 0.18$ & $0.91 \pm 0.08$ & $1.15 \pm 0.09$ & $0.29 \pm 0.02^{* *}$ & $2.09 \pm 0.50^{* *}$ & $0.57 \pm 0.04^{* *}$ & $2.39 \pm 0.23^{* * *}$ & $7.63 \pm 0.64^{* *}$ & $1.21 \pm 0.18$ & $0.66 \pm 0.22$ \\
\hline & $\begin{array}{l}\text { cAMP- } \\
\text { induced }\end{array}$ & 0 & $2.91 \pm 0.10$ & $1.19 \pm 0.18$ & $2.76 \pm 0.10$ & $27.27 \pm 6.26$ & $1.94 \pm 0.26$ & $4.80 \pm 1.41$ & $36.45 \pm 8.31$ & $11.47 \pm 2.91$ & $0.73 \pm 0.18$ & $19.49 \pm 5.69$ \\
\hline & & 0.25 & $2.75 \pm 0.18$ & $1.04 \pm 0.08$ & $2.87 \pm 0.18$ & $25.76 \pm 3.89$ & $1.95 \pm 0.23$ & $4.57 \pm 0.27$ & $57.16 \pm 16.27$ & $22.62 \pm 9.64$ & $0.82 \pm 0.18$ & $23.54 \pm 0.62$ \\
\hline & & 2.5 & $2.93 \pm 0.34$ & $1.20 \pm 0.15$ & $2.69 \pm 0.39$ & $17.51 \pm 3.71$ & $2.00 \pm 0.24$ & $4.59 \pm 0.84$ & $63.39 \pm 18.01$ & $18.46 \pm 2.61$ & $0.87 \pm 0.12$ & $26.64 \pm 1.79$ \\
\hline & & 25 & $3.14 \pm 0.09$ & $1.15 \pm 0.13$ & $2.51 \pm 0.27$ & $10.81 \pm 3.34^{*}$ & $2.47 \pm 0.62^{* *}$ & $1.94 \pm 0.05^{* *}$ & $62.41 \pm 7.34^{* *}$ & $40.38 \pm 2.69^{*}$ & $1.03 \pm 0.27$ & $17.20 \pm 1.62$ \\
\hline \multirow[t]{8}{*}{ AHTN } & Basal & 0 & $1.00 \pm 0.08$ & $1.02 \pm 0.21$ & $1.00 \pm 0.11$ & $1.01 \pm 0.18$ & $1.01 \pm 0.18$ & $1.01 \pm 0.21$ & $1.01 \pm 0.14$ & $1.01 \pm 0.15$ & $1.01 \pm 0.19$ & $1.00 \pm 0.07$ \\
\hline & & 0.25 & $0.95 \pm 0.15$ & $1.17 \pm 0.16$ & $1.04 \pm 0.04$ & $0.78 \pm 0.39$ & $1.05 \pm 0.04$ & $0.93 \pm 0.15$ & $1.17 \pm 0.26$ & $1.46 \pm 0.22$ & $1.40 \pm 0.16$ & $0.97 \pm 0.10$ \\
\hline & & 2.5 & $1.07 \pm 0.00$ & $1.37 \pm 0.11$ & $1.00 \pm 0.06$ & $0.64 \pm 0.10$ & $1.17 \pm 0.05$ & $0.71 \pm 0.07$ & $1.48 \pm 0.30$ & $1.47 \pm 0.13$ & $1.22 \pm 0.22$ & $0.70 \pm 0.06^{* *}$ \\
\hline & & 25 & $1.52 \pm 0.28$ & $1.25 \pm 0.33$ & $0.99 \pm 0.18$ & $0.37 \pm 0.03^{* *}$ & $1.52 \pm 0.08^{* *}$ & $0.53 \pm 0.06^{* *}$ & $2.87 \pm 0.65^{* *}$ & $7.20 \pm 1.68^{* * *}$ & $1.45 \pm 0.44$ & $0.55 \pm 0.09^{* *}$ \\
\hline & $\begin{array}{l}\text { cAMP- } \\
\text { induced }\end{array}$ & 0 & $3.61 \pm 0.18$ & $1.12 \pm 0.20$ & $3.42 \pm 0.41$ & $22.91 \pm 1.12$ & $1.89 \pm 0.37$ & $3.87 \pm 0.18$ & $39.16 \pm 5.17$ & $17.07 \pm 3.53$ & $0.61 \pm 0.29$ & $29.24 \pm 3.34$ \\
\hline & & 0.25 & $3.09 \pm 0.20$ & $1.14 \pm 0.24$ & $2.82 \pm 0.35$ & $28.36 \pm 2.06$ & $1.73 \pm 0.20$ & $3.76 \pm 0.50$ & $47.22 \pm 7.32$ & $23.46 \pm 6.73$ & $0.78 \pm 0.07$ & $26.94 \pm 2.70$ \\
\hline & & 2.5 & $3.50 \pm 0.39$ & $1.06 \pm 0.09$ & $2.90 \pm 0.41$ & $33.63 \pm 3.48^{* *}$ & $1.95 \pm 0.49$ & $4.10 \pm 1.16$ & $46.05 \pm 7.62$ & $27.12 \pm 8.42$ & $0.65 \pm 0.05$ & $30.37 \pm 1.65$ \\
\hline & & 25 & $3.02 \pm 0.36$ & $1.11 \pm 0.30$ & $2.80 \pm 0.21$ & $8.57 \pm 2.48^{* *}$ & $2.85 \pm 0.43^{*}$ & $1.56 \pm 0.27^{* * *}$ & $37.89 \pm 6.97$ & $43.83 \pm 15.78^{* *}$ & $0.72 \pm 0.17$ & $20.54 \pm 3.09^{*}$ \\
\hline
\end{tabular}

$p<0.05$ indicate statistically significant differences between treatment and control.

$p<0.01$ indicate statistically significant differences between treatment and control.

exposed to $25 \mu \mathrm{M}$ AHTN, CYP21 was down-regulated by $47 \%$ of the basal control and by $60 \%$ of the cAMP-induced control, while CYP11B2 was up-regulated by 7.20 -fold of the basal control and by 2.57 -fold of the cAMP-induced control.

\subsection{Effects of HHCB and AHTN on steroidogenic gene transcription involved in testosterone and $17 \beta$-estradiol biosynthesis}

Testosterone and $17 \beta$-estradiol are converted from progesterone via sequential reactions catalyzed by CYP17, $17 \beta H S D$, and CYP19 (Fig. 1). Under $25 \mu \mathrm{M}$ HHCB exposure, CYP17 was upregulated by 2.09 -fold of the basal control and by 2.50 -fold of the cAMP-induced control, whereas no significant differences were noted for $17 \beta H S D$ and CYP19. When H295R cells were exposed to $25 \mu \mathrm{M}$ AHTN, CYP17 was up-regulated by 2.17 -fold of the basal control and by 2.09-fold of the cAMP-induced control, while CYP19 was down-regulated by $43 \%$ of the basal control and by $45 \%$ of the cAMP-induced control. No significant differences were noted in transcription levels of $17 \beta H S D$ for AHTN.

\subsection{Effects of HHCB and AHTN on CYP17 enzyme activity involved in sex hormones biosynthesis}

CYP17 displays $17 \alpha$-hydroxylase and 17,20-lyase activity, that can be reflected by the ratio of $17 \alpha-\mathrm{OH}$-progesterone/progesterone and androstenedione $/ 17 \alpha-\mathrm{OH}$-progesterone, respectively (Fig. 1). As CYP17 is a bi-functional enzyme, $17 \alpha$-hydroxylase activity and 17,20-lyase activity were subsequently investigated to explore the potential mechanisms of HHCB and AHTN on altering sex hormone production. In HHCB basal and cAMP-induced treatments, $17 \alpha$-hydroxylase activity was increased in a dose-dependent manner (Fig. 4A), but 17,20-lyase activity was suppressed with increasing exposure concentrations of HHCB (Fig. 4B). In AHTN basal treatments, $17 \alpha$-hydroxylase activity was induced with the increasing concentration of AHTN (Fig. 4C, white dots), while 17,20-lyase activity was not significantly affected (Fig. 4D, white dots). In $25 \mu \mathrm{M}$ AHTN cAMP-induced treatments, $17 \alpha$-hydroxylase activity increased by 1.51 -fold (Fig. 4C, black dots), but 17,20-lyase activity was almost completely inhibited (Fig. 4D, black dots).

\subsection{Effects of HHCB and AHTN on MC2R transcription}

Binding to $M C 2 R$ is a necessary step for ACTH to stimulate steroid production. Therefore, $M C 2 R$ level is a fundamental factor determining the sensitivity and responsiveness of the adrenocortical cells to ACTH. MC2R transcription did not display significant changes after HHCB treatments (Fig. 5A). However, $M C 2 R$ transcription was up-regulated by 4.40 -fold in $25 \mu \mathrm{M}$ AHTN basal treatments, while $M C 2 R$ transcription was down-regulated by $55 \%$ in $25 \mu \mathrm{M}$ AHTN cAMP-induced treatments (Fig. 5B).

\section{Discussion}

In current study, progesterone production was found to be inhibited by $25 \mu \mathrm{M}$ HHCB. While for AHTN, the production of progesterone was significantly inhibited even when AHTN concentration was as low as $0.25 \mu \mathrm{M}$. The results above indicated that AHTN exhibits higher anti-progestagenic activity than HHCB, which agrees with previous reports that HHCB and AHTN are antagonists toward progesterone receptor in reporter gene bioassays, and the $\mathrm{IC}_{50}$ value of AHTN was lower than that of HHCB in the PR CALUX bioassay (Schreurs et al., 2005a). Because progesterone is a precursor to other hormones in the adrenal glands, significant inhibition of progesterone may lead to the reduction of downstream steroid hormones, which concurs with our observation that AHTN together with $1 \mathrm{mM} 8$-Br-cAMP resulted in the inhibition of aldosterone, cortisol, $17 \alpha-\mathrm{OH}$-progesterone and $17 \beta$-estradiol.

Cortisol production was found to be suppressed by the two tested PCMs at $25 \mu \mathrm{M}$. Cortisol is involved in a variety of physiological processes including stress response, immune response, and metabolism (Mommsen et al., 1999). Inhibition of cortisol suggested that HHCB and AHTN possess the potential to disturb physiological processes and might increase risk for Addison's disease (Ross et al., 2010). Interestingly, our results correlated well with those from an in vivo study conducted in our lab on the effects of AHTN on adrenal steroidogenesis using male Sprague-Dawley rats, which showed that plasma levels of corticosterone were significantly inhibited after rats were administrated with AHTN at the concentration of $0.5,5$, and $50 \mathrm{mg} \mathrm{kg}^{-1}$ for $28 \mathrm{~d}$ (unpublished data). The AHTN treatment decreased cortisol production in current study, which is in agreement with the rat study because the 

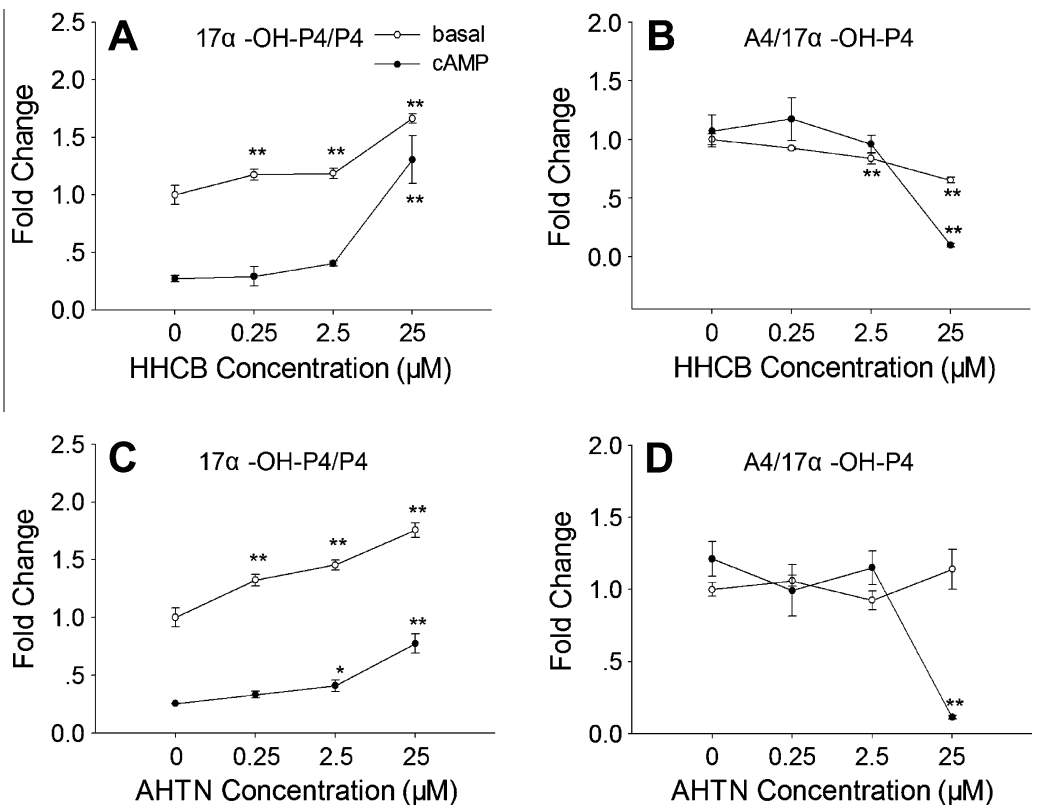

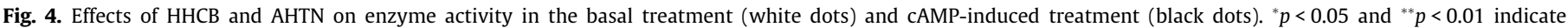
statistically significant differences between treatment and control.
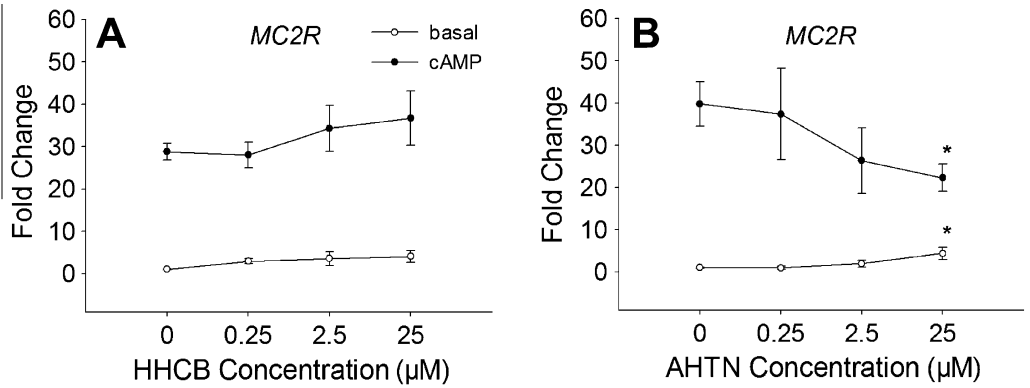

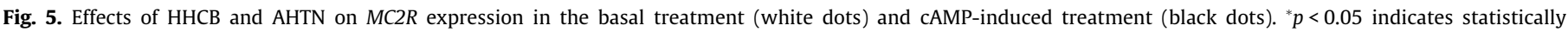
significant differences between treatment and control.

glucocorticosteroid is cortisol in humans while it is corticosterone in the rodents.

The concentrations of HHCB and AHTN in human adrenal glands have not been well characterized. However, considering the high blood flow and lipid content, HHCB and AHTN concentrations in the adrenal glands should be between those in blood (0.13-4.1 $\mathrm{ng} \mathrm{mL}^{-1}$ and $<0.8 \mathrm{ng} \mathrm{mL}^{-1}$ for HHCB and AHTN, respectively) (Hutter et al., 2005, 2010) and adipose tissue (12-798 $\mu \mathrm{g} \mathrm{kg}^{-1}$ fat and $<134 \mu \mathrm{g} \mathrm{kg}^{-1}$ fat for HHCB and AHTN, respectively) (Muller et al., 1996; Rimkus and Wolf, 1996; Kannan et al., 2005). Most of the effects observed in current study occurred at the exposure concentration of $25 \mu \mathrm{M}$, which is two or three orders higher than those detected in human blood. Given that the effects caused by PCMs at these concentrations in vitro could reflect those elicited by $\mathrm{PCMs}$ at lower concentrations in vivo, the current results suggest that the tested PCMs do affect steroidogenesis, but it still remains uncertain whether HHCB and AHTN exposure could pose risk to human health by affecting the adrenal hormone secretion at environmental relevant concentrations. Further studies are necessary to evaluate the potential effects caused by low concentrations of PCMs.

HMGR, StAR and CYP11A1 are rate-limiting steps in the conversion of cholesterol to steroid hormones. Transcription levels of HMGR, StAR and CYP11A1 were not significant changed upon exposure to the tested PCMs. The relatively constant transcription of these genes was also found in previous studies (Zhang et al., 2005; He et al., 2008), indicating that these three genes may not play a vital role in controlling the steroidogenic pathway in H295R cells. However, current study clearly indicated that HHCB and AHTN could directly decrease progesterone production by down-regulating $3 \beta H S D 2$, thereby influencing the steroidogenic pathways. Since $3 \beta H S D 2$ is widely distributed in the adrenal glands and gonads (Mason et al., 1998), the tested PCMs might also affect hormone production in gonads by down-regulating $3 \beta H S D 2$. $3 \beta H S D 2$ is an essential enzyme in the biosynthesis of mineralocorticoids, glucocorticoids and sex hormones. Assuming that $3 \beta H S D 2$ is one of the main targets, the inhibition of steroid hormones implied that the tested PCMs might have influences in other organs.

CYP21 is required for the synthesis of both aldosterone and cortisol. Inhibition of CYP21 may therefore lead to a decrease in the synthesis of cortisol and aldosterone. No significant changes in aldosterone production might be due to the up-regulation of CYP11B1 and CYP11B2 that could cancel out the effects of CYP21 down-regulation. The up-regulation of CYP11B2 and the downregulation of CYP21 were also observed in a previous study where H295R cells were exposed to sediment extracts containing polychlorinated biphenyls (PCBs) and organochlorine pesticides (OCPs) (Blaha et al., 2006). Considering that HHCB, AHTN, PCBs and OCPs are all polycyclic compounds, the gene transcription profiles obtained in this report further support the previous statement that 
chemicals with similar structures might possess similar endocrine disrupting mechanisms (Blaha et al., 2006). The reduction of cortisol production could be due to the down-regulation of CYP21 overthrow the up-regulation of CYP11B1 on the conversion of $17 \alpha$-OH-progesterone to cortisol.

CYP17 is a microsomal dual-functional enzyme, that is essential for the biosynthesis of androstenedione. High concentrations of HHCB and AHTN up-regulated CYP17 transcription and increased $17 \alpha$-hydroxylase activity, while decreasing the 17,20-lyase activity. The fact that androstenedione production was not affected combined with the up-regulation of CYP17 transcription might be explained by the induction of $17 \alpha$-hydroxylase activity which might overthrow the suppression of 17,20-lyase activity on the biosynthesis of androstenedione. The inhibition of $17 \beta$-estradiol in AHTN cAMP-induced treatments may be caused by the down-regulation of CYP19, which is the rate-limiting step in the conversion of testosterone into $17 \beta$-estradiol. A recent study also showed that AHTN is a potent inhibitor of CYP19 in the carp ovarian (Schnell et al., 2009). It is hypothesized in recent studies that alterations in aromatase (CYP19) activity represent a potential mechanism of endocrine disruption (Sanderson et al., 2002; Canton et al., 2005). The results of our current study and previous in vivo studies indicated that AHTN might cause endocrine disruption by altering aromatase activity. Since CYP17 and CYP19 are commonly present in the gonads and involved in sexual reproduction (Voutilainen and Miller, 1986; Canton et al., 2005), alterations of CYP17 and CYP19 transcription might disturb the balance between estrogens and androgens. Thus, further research is warranted to examine the potential effects of AHTN on reproductive behavior in vivo.

In the human adrenal cortex, steroidogenic enzymes are induced following an initial interaction of ACTH with MC2R o the cell membrane. It was found in current study that high concentrations of AHTN could affect the sensitivity of H295R cells to ACTH by influencing $M C 2 R$, suggesting that AHTN might also influence the steroidogenic modulation of ACTH by $M C 2 R$ transcription in addition to steroidogenic genes.

In this study, we showed that HHCB and AHTN could affect steroidogenesis through a similar mechanism and AHTN possessed a higher steroidogenic potency than HHCB. The results suggested that aromatic rings might play a key role in the alterations of hormone production and gene transcription, but clear relationships between chemical structure and adrenocortical toxicity could not be determined in current study. Further studies on quantitative structure activity relationships are required in order to properly assess the risk of PCMs.

\section{Conclusions}

In summary, this study demonstrated that HHCB and AHTN were capable of inhibiting progesterone and cortisol production mainly by the suppression of 3 $3 H S D 2$ and CYP21. In addition, high concentrations of AHTN could affect the sensitivity of H295R cells to ACTH by disrupting $M C 2 R$ transcription. However, effective doses used in the in vitro assay are considerably higher than those detected in the human and their biological significance in vivo is therefore uncertain. Further in vivo studies are needed to assess the potential health risks of PCMs.

\section{Acknowledgements}

This study was supported by the National Natural Science Foundation of China (20837003), the National High Technology Research and Development Program (863 Project, 2009AA062407) and Key Projects in the National Science \& Technology Pillar Program (2007BAC27B02-1a).

\section{References}

Bitsch, N., Dudas, C., Korner, W., Failing, K., Biselli, S., Rimkus, G., Brunn, H., 2002. Estrogenic activity of musk fragrances detected by the E-screen assay using human MCF-7 cells. Arch. Environ. Contam. Toxicol. 43, 257-264.

Blaha, L., Hilscherova, K., Mazurova, E., Hecker, M., Jones, P.D., Newsted, J.L., Bradley, P.W., Gracia, T., Duris, Z., Horka, I., Holoubek, I., Giesy, J.P., 2006. Alteration of steroidogenesis in H295R cells by organic sediment contaminants and relationships to other endocrine disrupting effects. Environ. Int. 32, 749757.

Canton, R.F., Sanderson, J.T., Letcher, R.J., Bergman, A., van den Berg, M., 2005 Inhibition and induction of aromatase (CYP19) activity by brominated flame retardants in H295R human adrenocortical carcinoma cells. Toxicol. Sci. 88, 447-455.

Damilakis, J., Tzedakis, A., Perisinakis, K., Papadakis, A.E., 2010. A method of estimating conceptus doses resulting from multidetector CT examinations during all stages of gestation. Med. Phys. 37, 6411-6420.

Furuta, C., Noda, S., Li, C., Suzuki, A.K., Taneda, S., Watanabe, G., Taya, K., 2008 Nitrophenols isolated from diesel exhaust particles regulate steroidogenic gene expression and steroid synthesis in the human H295R adrenocortical cell line. Toxicol. Appl. Pharmacol. 229, 109-120.

Gazdar, A.F., Oie, H.K., Shackleton, C.H., Chen, T.R., Triche, T.J., Myers, C.E., Chrousos, G.P., Brennan, M.F., Stein, C.A., Larocca, R.V., 1990. Establishment and characterization of a human adrenocortical carcinoma cell-line that expresses multiple pathways of steroid-biosynthesis. Cancer Res. 50, 5488-5496.

He, Y., Murphy, M.B., Yu, R.M.K., Lam, M.H.W., Hecker, M., Giesy, J.P., Wu, R.S.S., Lam, P.K.S., 2008. Effects of 20 PBDE metabolites on steroidogenesis in the H295R cell line. Toxicol. Lett. 176, 230-238.

Hecker, M., Giesy, J.P., 2008. Novel trends in endocrine disruptor testing: the H295R steroidogenesis assay for identification of inducers and inhibitors of hormone production. Anal. Bioanal. Chem. 390, 287-291.

Hu, Z., Shi, Y., Cai, Y., 2011. Concentrations, distribution, and bioaccumulation of synthetic musks in the Haihe River of China. Chemosphere 84, 1630-1635.

Hu, Z., Shi, Y., Niu, H., Cai, Y., Jiang, G., Wu, Y., 2010. Occurrence of synthetic musk fragrances in human blood from 11 cities in China. Environ. Toxicol. Chem. 29 , 1877-1882.

Hutter, H.P., Wallner, P., Hartl, W., Uhl, M., Lorbeer, G., Gminski, R., MerschSundermann, V., Kundi, M., 2010. Higher blood concentrations of synthetic musks in women above fifty years than in younger women. Int. J. Hyg. Environ. Health 213, 124-130.

Hutter, H.P., Wallner, P., Moshammer, H., Hartl, W., Sattelberger, R., Lorbeer, G., Kundi, M., 2005. Blood concentrations of polycyclic musks in healthy young adults. Chemosphere 59, 487-492.

Johansson, M.K., Sanderson, J.T., Lund, B.O., 2002. Effects of 3-MeSO2-DDE and some CYP inhibitors on glucocorticoid steroidogenesis in the H295R human adrenocortical carcinoma cell line. Toxicol. Vitro 16, 113-121.

Kannan, K., Reiner, J.L., Yun, S.H., Perrotta, E.E., Tao, L., Johnson-Restrepo, B., Rodan, B.D., 2005. Polycyclic musk compounds in higher trophic level aquatic organisms and humans from the United States. Chemosphere 61, 693-700.

Li, L.A., Chang, Y.C., Wang, C.J., Tsai, F.Y., Jong, S.B., Chung, B.C., 2004. Steroidogenic factor 1 differentially regulates basal and inducible steroidogenic gene expression and steroid synthesis in human adrenocortical H295R cells. J. Steroid Biochem. Mol. Biol. 91, 11-20.

Li, L.A., Wang, P.W., 2005. PCB126 induces differential changes in androgen, cortisol, and aldosterone biosynthesis in human adrenocortical H295R cells. Toxicol. Sci. 85, 530-540.

Livak, K.J., Schmittgen, T.D., 2001. Analysis of relative gene expression data using real-time quantitative PCR and the 2(T)(-Delta Delta C) method. Methods 25, 402-408.

Ma, Y., Liu, C., Lam, P.K., Wu, R.S., Giesy, J.P., Hecker, M., Zhang, X., Zhou, B., 2011. Modulation of steroidogenic gene expression and hormone synthesis in H295R cells exposed to PCP and TCP. Toxicology 282, 146-153.

Mason, J.I., Naville, D., Evans, B.W., Thomas, J.L., 1998. Functional activity of 3betahydroxysteroid dehydrogenase/isomerase. Endocr. Res. 24, 549-557.

Mommsen, T.P., Vijayan, M.M., Moon, T.W., 1999. Cortisol in teleosts: dynamics, mechanisms of action, and metabolic regulation. Rev. Fish Biol. Fish 9, 211-268.

Muller, S., Schmid, P., Schlatter, C., 1996. Occurrence of nitro and non-nitro benzenoid musk compounds in human adipose tissue. Chemosphere 33, 17-28.

Oskarsson, A., Ulleras, E., Plant, K.E., Hinson, J.P., Goldfarb, P.S., 2006. Steroidogenic gene expression in H295R cells and the human adrenal gland: adrenotoxic effects of lindane in vitro. J. Appl. Toxicol. 26, 484-492.

Ramskov, T., Selck, H., Salvito, D., Forbes, V.E., 2009. Individual- and populationlevel effects of the synthetic musk, Hhcb, on the deposit-feeding polychaete, capitella Sp I. Environ. Toxicol. Chem. 28, 2695-2705.

Ribelin, W.E., 1984. The effects of drugs and chemicals upon the structure of the adrenal gland. Fundam. Appl. Toxicol. 4, 105-119.

Rimkus, G.G., Wolf, M., 1996. Polycyclic musk fragrances in human adipose tissue and human milk. Chemosphere 33, 2033-2043.

Ross, I.L., Levitt, N.S., Van der Walt, J.S., Pillay, T.S., 2010. Monitoring of replacement therapy in patients with Addison's disease, using salivary cortisol day curve measurements. Endocr. J. 57, S642-S644.

Sanderson, J.T., 2006. The steroid hormone biosynthesis pathway as a target for endocrine-disrupting chemicals. Toxicol. Sci. 94, 3-21.

Sanderson, J.T., Boerma, J., Lansbergen, G.W.A., van den Berg, M., 2002. Induction and inhibition of aromatase (CYP19) activity by various classes of pesticides in 
H295R human adrenocortical carcinoma cells. Toxicol. Appl. Pharmacol. 182, 44-54.

Schnell, S., Martin-Skilton, R., Fernandes, D., Porte, C., 2009. The interference of nitro- and polycyclic musks with endogenous and xenobiotic metabolizing enzymes in carp: an in vitro study. Environ. Sci. Technol. 43, 9458-9464.

Schreurs, R.H.M.M., Legler, J., Artola-Garicano, E., Sinnige, T.L., Lanser, P.H., Seinen, W., van der Burg, B., 2004. In vitro and in vivo antiestrogenic effects of polycyclic musks in zebrafish. Environ. Sci. Technol. 38, 997-1002.

Schreurs, R.H.M.M., Sonneveld, E., Jansen, J.H.J., Seinen, W., van der Burg, B., 2005a. Interaction of polycyclic musks and UV filters with the estrogen receptor (ER), androgen receptor (AR), and progesterone receptor (PR) in reporter gene bioassays. Toxicol. Sci. 83, 264-272.

Schreurs, R.H.M.M., Sonneveld, E., van der Saag, P.T., van der Burg, B., Seinen, W. 2005b. Examination of the in vitro (anti) estrogenic, (anti) androgenic and (anti) dioxin-like activities of tetralin, indane and isochroman derivatives using receptor-specific bioassays. Toxicol. Lett. 156, 261-275.

Seinen, W., Lemmen, J.C., Pieters, R.H.H., Verbruggen, E.M.J., van der Burg, B., 1999. AHTN and HHCB show weak estrogenic - but no uterotrophic activity. Toxicol. Lett. 111, 161-168.
Sewer, M.B., Waterman, M.R., 2003. ACTH modulation of transcription factors responsible for steroid hydroxylase gene expression in the adrenal cortex. Microsc. Res. Tech. 61, 300-307.

Voutilainen, R., Miller, W.L., 1986. Developmental expression of genes for the stereoidogenic enzymes P450scc (20,22-Desmolase), P450c17 (17-AlphaHydroxylase 17,20-Lyase), and P450c21 (21-Hydroxylase) in the human-fetus. J. Clin. Endocrinol. Metab. 63, 1145-1150.

Yamauchi, R., Ishibashi, H., Hirano, M., Mori, T., Kim, J.W., Arizono, K., 2008. Effects of synthetic polycyclic musks on estrogen receptor, vitellogenin, pregnane $\mathrm{X}$ receptor, and cytochrome P450 3A gene expression in the livers of male medaka (Oryzias latipes). Aquat. Toxicol. 90, 261-268.

Zeng X.Y, Mai, B.X. Sheng, G.Y. Luo, X.J. Shao, W.L. An, T.C., Fu, J. 2008 Distribution of polycyclic musks in surface sediments from the Pearl River Delta and Macao coastal region, South China. Environ. Toxicol. Chem. 27, 1823.

Zhang, X.W., Yu, R.M.K., Jones, P.D., Lam, G.K.W., Newsted, J.L., Gracia, T., Hecker, M., Hilscherova, K., Sanderson, J.T., Wu, R.S.S., Giesy, J.P., 2005. Quantitative RT-PCR methods for evaluating toxicant-induced effects on steroidogenesis using the H295R cell line. Environ. Sci. Technol. 39, 2777-2785. 